\title{
The impact of age and preoperative health-related quality of life on patient-reported improvements after total hip arthroplasty
}

This article was published in the following Dove Press journal:

Clinical Interventions in Aging

14 November 2017

Number of times this article has been viewed

\author{
Peter K Aalund \\ Eva N Glassou \\ Torben B Hansen \\ University Clinic for Hand, Hip and \\ Knee Surgery, Regional Hospital \\ West Jutland, Aarhus University, \\ Holstebro, Denmark
}

Background: Total hip arthroplasty (THA) is a common surgical procedure and approximately 9,500 of these surgeries are performed annually in Denmark. The operation is considered effective and successful with respect to complications, mortality, and implant survival. However, using patient-reported outcome measures, up to $10 \%$ of patients are not satisfied with the outcome of their operation. To address this, it is important to find out why some patients experience impaired outcomes after THA. The purpose of this study was to investigate the impact of age and preoperative health-related quality of life (HRQoL) on improvements in HRQoL after THA.

Methods: A cohort study was conducted with follow-up at 3 and 12 months. Patients were included from September 2008 to December 2013. We analyzed 1,283 THA cases. HRQoL was measured using the EuroQol-5 Domain. Analyses were carried out with multiple linear regression and adjusted for relevant variables available in the data set.

Results: A significant positive association was found between age and HRQoL outcomes for patients who underwent THA at both 3 ( $\beta$ [regression coefficient] 0.0026 , confidence interval [CI] $0.0013 ; 0.0039, p<0.001)$ and $12(\beta 0.0020 \mathrm{CI} 0.0008 ; 0.0032, p=0.001)$ months of follow-up. A clinically relevant change was achieved with an increase in age of 12-15 years. A significant negative association was found between preoperative HRQoL and HRQoL outcomes at both $3(\beta-0.841 \mathrm{CI}-0.886 ;-0.795, p<0.001)$ and $12(\beta-0.804 \mathrm{CI}-0.844 ;-0.764$, $p<0.001$ ) months of follow-up.

Conclusion: Contrary to our expectations, older patients had more improvements in HRQoL outcomes after THA. A high preoperative HRQoL seems to inhibit improvements in HRQoLs after THA.

Keywords: total hip arthroplasty, THA, health-related quality of life, HRQoL, EuroQol-5D, patient-reported outcome

\section{Plain language summary}

Hip replacement is a common procedure with approximately 9,500 surgeries performed annually in Denmark. The operation is considered effective and successful with respect to complications, mortality, and implant survival. However, up to $10 \%$ of patients are not satisfied with the results of the operation. To address this, it is important to determine why some patients experience impaired benefits, and the purpose of this study was to investigate the impact of age and preoperative health-related quality of life (HRQoL) on patient improvement after the operation. Information was collected via questionnaires provided to the patients between September 2008 and December 2013. This study included 1,283 patients.

Contrary to our expectations, we found that older patients had a better improvement in HRQoL than younger patients with respect to hip replacement. Moreover, high preoperative HRQoL seems to inhibit improvement in HRQoL after THA. Our results suggest that age
Correspondence: Peter K Aalund
University Clinic for Hand, Hip and Knee Surgery, Regional Hospital West Jutland, Aarhus University, Lægårdvej I2, Holstebro 7500, Denmark Email petaal@rm.dk $\mathrm{BY}$
hereby accept the Terms. Non-commercial uses of the work are permitted without any further permission from Dove Medical Press Limited, provided the work is properly attributed. For permission hereby accept the Terms. Non-commercial uses of the work are permitted without any further permission from Dove Medict
for commercial use of this work, please see paragraphs 4.2 and 5 of our Terms (https://www.dovepress.com/terms.php). 
should not be a concern with respect to the HRQoL benefits when considering hip replacement in older patients. Conversely, surgeons should be aware of the risk of limited improvement in HRQoL when offering surgery to people with high preoperative HRQoL.

\section{Introduction}

Total hip arthroplasty (THA) is a common surgical procedure with approximately 9,500 procedures performed annually in Denmark. ${ }^{1}$ This corresponds to an incidence of 165 per 100,000 citizens. The aim of the procedure is to improve function and quality of life. The procedure is considered effective and successful with regard to complications, mortality, and prosthesis survival. ${ }^{1}$ However, using patient-reported outcome measures (PROMs), approximately $10 \%$ of patients report some degree of dissatisfaction after surgery. ${ }^{2-4}$ To address this, it is important to determine why some patients experience impaired outcomes after this operation.

Sex, age, and preoperative quality of life are factors that appear to have an effect on patient reported outcomes after surgery. ${ }^{5-9}$ In addition, conditions such as pain, ${ }^{5}$ function, ${ }^{10,11}$ comorbidity, ${ }^{12,13} \mathrm{BMI},{ }^{14-16}$ and underlying diseases prior to the operation ${ }^{17,18}$ seem to play a role. Furthermore, expectations before surgery ${ }^{4,19,20}$ and socioeconomic status ${ }^{21,22}$ may influence patients' reporting postoperatively. However, there are conflicting results regarding existing research and therefore more study is needed.

The purpose of this study was to investigate the impact of age and preoperative health-related quality of life (HRQoL) on the improvement in HRQoL after primary elective THA. Our hypothesis was that older patients experienced fewer benefits from THA than younger patients due to other conditions limiting the patients' performance after surgery. Furthermore, the high preoperative HRQoL was hypothesized to decrease patients' overall improvements after the operation.

\section{Materials and methods}

\section{Study design}

A cohort study was conducted with a baseline preoperative registration, and follow-up was performed at 3 and 12 months. Data were collected by questionnaires completed by patients at the Regional Hospital West Jutland in Denmark from September 2008 to December 2013.

\section{Population}

During the study period, 2,166 primary elective THAs resulting from osteoarthritis were performed at the hospital. Of these patients, 1,086 and 1,283 were available for analysis at 3 and 12 months, respectively (Figure 1). Inclusion criteria

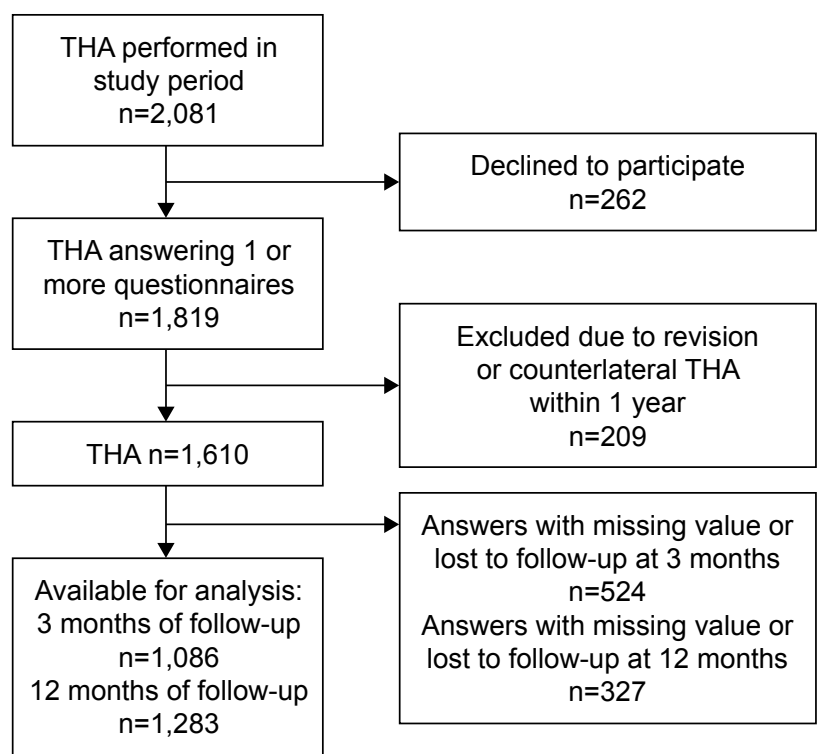

Figure I Flowchart over study population. Abbreviation: THA, total hip arthroplasty.

were first primary THA, an age of 35 years or older, and the ability to read and understand Danish. If an individual received a revision or a counter-lateral THA within 1 year, data from first primary THA were excluded.

\section{EuroQol-5 Domain}

HRQoL was measured using the EuroQol-5 Domain (EQ-5D). EQ-5D is a short generic questionnaire, which consists of five questions regarding mobility, personal care, activity, pain/discomfort, and anxiety/depression. ${ }^{23}$ We used the three-level version. The possible answers indicating magnitude of symptoms included no problems, moderate problems, or extreme problems. Responders' answers were converted to a score from -0.6 to 1.0 , where 1.0 was the best possible HRQoL. Furthermore, the responses were converted into a single weighted Danish index score. ${ }^{24}$

\section{THA}

THA patients were assigned to a well-defined fast-track program, ${ }^{25}$ without receiving any formalized physiotherapy after discharge from hospital except in patients who mentally or physically were not able to follow a self-training program. Fast-track surgery was defined as the synergistic beneficial effect on convalescence achieved by adding multimodal evidence-based care principles and combining these with optimized logistics. ${ }^{26,27}$ Both cemented and uncemented arthroplasties were included in the study, and all operations were performed through a posterior approach by consultants or residents under direct supervision of consultants. 


\section{Exposures}

Exposures included age measured as a continuous variable and preoperative EQ-5D scores.

\section{Outcomes}

Outcomes were changes in patient-reported HRQoL measured as the difference between preoperative and postoperative EQ-5D scores at 0-3 and 0-12 months, respectively.

\section{Statistical analysis}

Descriptive characteristics were presented as means with standard deviations (SD) if data were normally distributed and as medians with interquartile range if data were not normally distributed. Analyses were carried out with multiple linear regressions. Analyses regarding the impact of age were adjusted for sex. Analyses regarding impact of preoperative HRQoL were adjusted for sex and age. Results were presented as regression coefficients with $95 \%$ confidence intervals (CI) and $p$-values. $p$-values $<0.05$ were considered significant. The minimum clinically relevant difference was set at $0.03 .^{28}$

Analyses were performed using the Stata Statistical Software, Release 14.0 (StatCorp LP, College Station, TX, USA).

\section{Ethics}

\section{Trial registration}

The study was approved by the research ethics committee of Central Region Denmark, and no further specific approval was required. The study was registered with the Danish
Data Protection Agency (j.nr. 2007-41-1197). The patients provided written informed consent.

\section{Results}

Patient characteristics are shown in Table 1. Of the 1,610 patients undergoing THAs, $47.8 \%$ were women. The mean age was 68.9 years (SD 10.15). The median EQ-5D index score was 0.72 (CI $0.59 ; 0.77$ ) preoperatively, but this reached 0.82 (CI $0.77 ; 1.00)$ and 1 (CI $0.78 ; 1.00)$ at 3 and 12 months of follow-up.

\section{Impact of age}

Significant associations between age and change in HRQoL were found at both 3 and 12 months of follow-up (Table 2). Estimates from adjusted analysis were 0.0026 (CI 0.0013; 0.0039 ) at 3 months of follow-up and 0.0020 (CI 0.0008; 0.0032 ) at 12 months of follow-up. Interpretations of these estimates corresponded to the difference in HRQoL scores between two persons of the same sex and 1 year of age difference. Levels of minimal clinically relevant EQ-5Ddifferences were determined by an age difference of 12 years at 3 months of follow-up and 15 years at 12 months of follow-up. Because the estimates were positive, this meant that HRQoLs were higher in an older individual compared to a younger person.

\section{Impact of preoperative HRQoL}

Significant associations between preoperative HRQoL and changes in HRQoL were also found at both 3 and 12 months

Table I Patient characteristics for THA operated at Regional Hospital West Jutland, Denmark September 2008-December 20 I3, who answered one or more of three questionnaires

\begin{tabular}{|c|c|c|c|c|c|}
\hline & Total & $\begin{array}{l}\text { Age } \\
<60 \text { years }\end{array}$ & $\begin{array}{l}\text { Age } \\
60-69 \text { years }\end{array}$ & $\begin{array}{l}\text { Age } \\
70-79 \text { years }\end{array}$ & $\begin{array}{l}\text { Age } \\
>79 \text { years }\end{array}$ \\
\hline Total, n (\%) & $1,610(100)$ & $329(100)$ & $571(100)$ & $548(100)$ & $169(100)$ \\
\hline Women & $769(47.8)$ & $129(39.2)$ & $251(44)$ & $277(50.6)$ & $113(66.9)$ \\
\hline Men & $84 \mid(52.2)$ & $200(60.8)$ & $320(56)$ & $27 \mid(49.4)$ & $56(33.1)$ \\
\hline Age, mean (SD) & $68.9(10.15)$ & & & & \\
\hline \multicolumn{6}{|c|}{ EQ-5D index score } \\
\hline \multicolumn{6}{|l|}{ Preoperatively } \\
\hline Mean & 0.63 & 0.64 & 0.65 & 0.63 & 0.52 \\
\hline SD & 0.20 & 0.18 & 0.19 & 0.20 & 0.23 \\
\hline Median & 0.72 & 0.72 & 0.72 & 0.72 & 0.59 \\
\hline \multicolumn{6}{|l|}{3 months } \\
\hline Mean & 0.85 & 0.82 & 0.86 & 0.89 & 0.81 \\
\hline SD & 0.15 & 0.17 & 0.14 & 0.14 & 0.15 \\
\hline Median & 0.82 & 0.82 & 0.83 & 0.84 & 0.82 \\
\hline \multicolumn{6}{|l|}{12 months } \\
\hline Mean & 0.89 & 0.88 & 0.91 & 0.90 & 0.82 \\
\hline SD & 0.14 & 0.16 & 0.13 & 0.14 & 0.15 \\
\hline Median & 1.00 & 1.00 & 1.00 & 1.00 & 0.82 \\
\hline
\end{tabular}

Abbreviations: EQ-5D, EuroQol-5 Domain; SD, standard deviation; THA, total hip arthroplasty. 
Table 2 Association between age and change between preoperative and postoperative patient-reported HRQoL

\begin{tabular}{|c|c|c|c|c|}
\hline & \multicolumn{2}{|c|}{ Unadjusted analysis } & \multicolumn{2}{|c|}{ Adjusted analysis ${ }^{a}$} \\
\hline & $\begin{array}{l}\text { Coefficients } \\
(95 \% \mathrm{Cl})\end{array}$ & $p$-value & $\begin{array}{l}\text { Coefficients } \\
(95 \% \mathrm{Cl})\end{array}$ & $p$-value \\
\hline $\begin{array}{l}0-3 \text { months, } \\
n=1,086\end{array}$ & $\begin{array}{l}0.0026 \\
(0.0013-0.0039)\end{array}$ & I & $\begin{array}{l}0.0026 \\
(0.0013 ; 0.0039)\end{array}$ & 01 \\
\hline $\begin{array}{l}0-12 \text { months, } \\
n=1,283\end{array}$ & $\begin{array}{l}0.0021 \\
(0.0009-0.0033)\end{array}$ & $<0.001$ & $\begin{array}{l}0.0020 \\
(0.0008 ; 0.0032)\end{array}$ & 0.001 \\
\hline
\end{tabular}

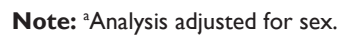

Abbreviations: $\mathrm{Cl}$, confidence interval; $\mathrm{HRQ}$ oL, health-related quality of life.

of follow-up (Table 3). Estimates from adjusted analyses were -0.841 (CI $-0.886 ;-0.795)$ at 3 months of follow-up and -0.804 (CI $-0.844 ;-0.764)$ at 12 months of follow-up. Example of interpretations include the following: at a difference at 1.0 in preoperative EQ-5D between two individuals of the same sex and gender, there was a difference in EQ-5D change at approximately 0.8 at 12 months of follow-up. Estimates that were negative indicated that, when a difference in preoperative HRQoL appears between two individuals, the case with the highest score achieved the minimum HRQoL outcome.

\section{Discussion}

Contrary to our expectations, we found that older THA patients had a higher HRQoL change compared to younger individuals at both 3 and 12 months of follow-up. A significant change was achieved at 12 years ( 3 months follow-up) and 15 years (12 months follow-up) for the age differences. Moreover, we found a lower HRQoL change with increasing preoperative HRQoL at both 3 and 12 months of follow-up.

This study confirms data regarding PROMs, which are highly sought when evaluating outcomes and degrees of successfully completed operations. Moreover, we investigated a relatively large population from a large catchment area, which increased the value of the data.

Table 3 Association between preoperative HRQoL and change between preoperative and postoperative patient-reported HRQoL

\begin{tabular}{|c|c|c|c|c|}
\hline \multirow[t]{2}{*}{ Follow-up } & \multicolumn{2}{|c|}{ Unadjusted analysis } & \multicolumn{2}{|c|}{ Adjusted analysis $^{a}$} \\
\hline & $\begin{array}{l}\text { Coefficients } \\
(95 \% \mathrm{CI})\end{array}$ & $p$-value & $\begin{array}{l}\text { Coefficients } \\
(95 \% \mathrm{Cl})\end{array}$ & $p$-value \\
\hline $\begin{array}{l}0-3 \text { months, } \\
n=1,086\end{array}$ & $\begin{array}{l}-0.842 \\
(-0.887 ;-0.797)\end{array}$ & $<0.001$ & $\begin{array}{l}-0.841 \\
(-0.886 ;-0.795)\end{array}$ & $<0.001$ \\
\hline $\begin{array}{l}0-12 \text { months, } \\
n=1,283\end{array}$ & $\begin{array}{l}-0.799 \\
(-0.839 ;-0.759)\end{array}$ & $<0.001$ & $\begin{array}{l}-0.804 \\
(-0.844 ;-0.764)\end{array}$ & $<0.001$ \\
\hline
\end{tabular}

Note: analysis adjusted for sex and age.

Abbreviations: $\mathrm{Cl}$, confidence interval; $\mathrm{HRQ}$ L, health-related quality of life.
However, a substantial number of patients were not included in this analysis. This was partly due to missing answers in questionnaires and patients who declined to participate or were lost during follow-up. In terms of age, sex, and preoperative EQ-5D scores, these patients were not significantly different from the study group. Therefore, this dropout rate was considered to be a non-differentiated selection, leading only to a weakening of the estimates. We did not have any information about those who declined to participate. However, they represent only a relatively small proportion of the total population, and are therefore assessed to have only limited impacts on these estimates.

EQ-5D has been criticized for problems regarding floor and ceiling effects when used for measuring changes over time or in relation to a specific intervention. For example, patients with a high score before surgery only have limited room for improvement on the scale. This may cause a ceiling effect, and may partly explain our findings with limited improvements in patients with a high preoperative HRQoL. Conversely, patients with low scores before surgery have greater opportunities for improvement on the EQ-5D scale. This allows the size of EQ-5D change to be conditional on the preoperative score. A newer version of EQ-5D with five instead of three answering options has been developed to address these problems, but this tool was not available at the start of this cohort. Nevertheless, EQ-5D is generally considered a valid tool for measuring HRQoL. ${ }^{29-31}$

Different factors seem to affect PROMs after THA operations. In this study, it was not possible to adjust our analyses for all of these factors. Other factors, such as pain, comorbidity, and expectations, might therefore explain some of the association we found. This is a substantial limitation of this study and leads to the risk of residual confounding. To what extent this has been the case was not possible to clarify in our study.

In a nationwide cohort of more than 27,000 THA patients from the Swedish registry of arthroplasty, Gordon et $\mathrm{al}^{7} \mathrm{did}$ not find a positive association between age and HRQoL change measured with EQ-5D. The results were based on patients operated on the basis of primary osteoarthritis, who had a follow-up at 12 months postoperatively. Their analysis showed a nonlinear relationship with a tendency towards negative effects of age on HRQoL changes at the age of 70 years. The analysis was adjusted for sex, previous contralateral hip surgery, pain, Charnley classification, and preoperative HRQoL. It tested for conditions that are not contained in the current study, which may explain some of the differences between the results and the findings in our study. 
However, it should be mentioned that another study by Gordon et $\mathrm{al}^{32}$ found that Danish THA patients had an overall higher EQ-5D index 1 year after surgery compared to a similar Swedish population. This was the case despite the fact that Danish and Swedish populations are culturally comparable. Distributions between age groups did not appear in their study, but this country difference may help explain these contradictory results.

Regarding the impact of preoperative HRQoL, Gordon et $\mathrm{al}^{7}$ found that patients with low preoperative EQ-5D scores had the greatest EQ-5D-change, even though they did not obtain the absolute level of patients with higher preoperative EQ-5D scores. As higher preoperative EQ-5D scores decreased in patients whose score was close to the ceiling of the measuring instrument, there was an average estimated decline in their EQ-5D at 1-year follow-up postoperatively. Alzahrani et $\mathrm{al}^{133}$ found that both patients with high and low preoperative function had significant improvements in the HRQoL scores. However, this improvement was substantially greater in the low function group, resulting in no difference in the HRQoL outcomes of the two groups at final follow-up at 2 years after the operation.

Vogl et $\mathrm{al}^{9}$ conducted a prospective cohort study of 321 THA patients with 6 months of follow-up. The lower the preoperative score, the greater the changes in the EQ-5D score. The follow-up time was not directly comparable. However, the results support our findings in the current study.

The present study has several limitations. As described by Shan et al, ${ }^{34}$ there are many factors that can influence midto long-term HRQoL that we did not include in our study. In particular, comorbidities, medication use, psychological profile, and social support factors impact HRQoL outcomes and are likely to worsen with time after the 12 months that we used as time frame. Also, implant failure leading to revision occurs later, which may possibly lead to a negative long-term effect on HRQoL. However, as 10-years failure rate of THA is below $5 \%$, the effect may be limited.

\section{Conclusion}

Contrary to our expectations, age seems to increase improvements in HRQoL after THA operations. High preoperative HRQoL scores seem to limit the improvement in HRQoL after THA. Our results suggest that age should not be a concern with respect to the benefits measured in terms of HRQoL when considering hip arthroplasty surgery for older patients. Conversely, surgeons should be aware of the risks of limited improvements in HRQoL when offering surgery to people with high preoperative HRQoL.

\section{Disclosure}

The authors report no conflicts of interest in this work.

\section{References}

1. Styregruppen for Dansk Hoftealloplastikregister. Dansk hoftealloplastik register - national årsrapport 2015. [Danish Hip Alloplasty Register - National Annual Report 2015]. 2015. Danish.

2. Anakwe RE, Jenkins PJ, Moran M. Predicting dissatisfaction after total hip arthroplasty: a study of 850 patients. J Arthroplasty. 2011; 26(2):209-213.

3. Mancuso CA, Salvati EA, Johanson NA, Peterson MG, Charlson ME. Patients' expectations and satisfaction with total hip arthroplasty. J Arthroplasty. 1997;12(4):387-396.

4. Arden NK, Kiran A, Judge A, et al. What is a good patient reported outcome after total hip replacement? Osteoarthritis Cartilage. 2011; 19(2):155-162.

5. Mannion AF, Impellizzeri FM, Naal FD, Leunig M. Women demonstrate more pain and worse function before THA but comparable results 12 months after surgery. Clin Orthop Relat Res. 2015;473(12): 3849-3857.

6. Kostamo T, Bourne RB, Whittaker JP, McCalden RW, MacDonald SJ No difference in gender-specific hip replacement outcomes. Clin Orthop Relat Res. 2009;467(1):135-140.

7. Gordon M, Greene M, Frumento P, Rolfson O, Garellick G, Stark A. Age- and health-related quality of life after total hip replacement: decreasing gains in patients above 70 years of age. Acta Orthop. 2014; 85(3):244-249.

8. Lawless BM, Greene M, Slover J, Kwon YM, Malchau H. Does age or bilateral disease influence the value of hip arthroplasty? Clin Orthop Relat Res. 2012;470(4):1073-1078.

9. Vogl M, Wilkesmann R, Lausmann C, Hunger M, Plotz W. The impact of preoperative patient characteristics on health states after total hip replacement and related satisfaction thresholds: a cohort study. Health Qual Life Outcomes. 2014;12:108.

10. Johansson HR, Bergschmidt P, Skripitz R, Finze S, Bader R, Mittelmeier W. Impact of preoperative function on early postoperative outcome after total hip arthroplasty. J Orthop Surg (Hong Kong). 2010;18(1):6-10.

11. Berliner JL, Brodke DJ, Chan V, SooHoo NF, Bozic KJ. John Charnley award: preoperative patient-reported outcome measures predict clinically meaningful improvement in function after THA. Clin Orthop Relat Res. 2016;474(2):321-329.

12. Greene ME, Rolfson O, Gordon M, Garellick G, Nemes S. Standard comorbidity measures do not predict patient-reported outcomes 1 year after total hip arthroplasty. Clin Orthop Relat Res. 2015;473(11): 3370-3379.

13. Rat AC, Guillemin F, Osnowycz G, et al. Total hip or knee replacement for osteoarthritis: mid- and long-term quality of life. Arthritis Care Res (Hoboken). 2010;62(1):54-62.

14. Liljensøe A, Lauersen JO, Søballe K, Mechlenburg I. Overweight preoperatively impairs clinical outcome after knee arthroplasty: a cohort study of 197 patients 3-5 years after surgery. Acta Orthop. 2013;84(4): 392-397.

15. Dowsey MM, Liew D, Stoney JD, Choong PF. The impact of pre-operative obesity on weight change and outcome in total knee replacement: a prospective study of 529 consecutive patients. J Bone Joint Surg Br. 2010; 92(4):513-520.

16. Järvenpää J, Kettunen J, Soininvaara T, Miettinen H, Kroger H. Obesity has a negative impact on clinical outcome after total knee arthroplasty. Scand J Surg. 2012;101(3):198-203.

17. Ieiri A, Tushima E, Ishida K, Abe S, Inoue M, Masuda T. What predicts 36-item health survey version 2 after total hip arthroplasty. Arch Phys Med Rehabil. 2013;94(5):902-909.

18. Lunebourg A, Parratte S, Gay A, Ollivier M, Garcia-Parra K, Argenson JN. Lower function, quality of life, and survival rate after total knee arthroplasty for posttraumatic arthritis than for primary arthritis. Acta Orthop. 2015;86(2):189-194. 
19. Palazzo C, Jourdan C, Descamps S, et al. Determinants of satisfaction 1 year after total hip arthroplasty: the role of expectations fulfilment. BMC Musculoskelet Disord. 2014;15(1):53.

20. Haanstra TM, Van Den Berg T, Ostelo RW, et al. Systematic review: do patient expectations influence treatment outcomes in total knee and total hip arthroplasty? Health Qual Life Outcomes. 2012;10:152.

21. Greene ME, Rolfson O, Nemes S, Gordon M, Malchau H, Garellick G. Education attainment is associated with patient-reported outcomes: findings from the Swedish hip arthroplasty register. Clin Orthop Relat Res. 2014;472(6):1868-1876.

22. Dowsey MM, Nikpour M, Choong PF. Outcomes following large joint arthroplasty: does socio-economic status matter? BMC Musculoskelet Disord. 2014;15(1):148.

23. EuroQol Research Foundation. Eq-5d [updated 2017]. Available from: http://www.euroqol.org/. Accessed May 1, 2017.

24. Sørensen J, Davidsen M, Gudex C, Pedersen KM, Brønnum-Hansen H. Danish EQ-5D population norms. Scand J Public Health. 2009;37(5): 467-474.

25. Husted H, Solgaard S, Hansen TB, Soballe K, Kehlet H. Care principles at four fast-track arthroplasty departments in Denmark. Dan Med Bull. 2010;57(7):A4166.

26. Kehlet H, Wilmore DW. Evidence-based surgical care and the evolution of fast-track surgery. Ann Surg. 2008;248(2):189-198.

27. Husted H. Fast-track hip and knee arthroplasty: clinical and organizational aspects. Acta Orthop Suppl. 2012;83(346):1-39.
28. Wyrwich KW, Tierney WM, Babu AN, Kroenke K, Wolinsky FD. A comparison of clinically important differences in health-related quality of life for patients with chronic lung disease, asthma, or heart disease. Health Serv Res. 2005;40(2):577-591.

29. Brazier J, Jones N, Kind P. Testing the validity of the Euroqol and comparing it with the SF-36 health survey questionnaire. Qual Life Res. 1993;2(3):169-180.

30. van Agt HM, Essink-Bot ML, Krabbe PF, Bonsel GJ. Test-retest reliability of health state valuations collected with the EuroQol questionnaire. Soc Sci Med. 1994;39(11):1537-1544.

31. Tidermark J, Bergstrom G, Svensson O, Tornkvist H, Ponzer S. Responsiveness of the EuroQol (EQ 5-D) and the SF-36 in elderly patients with displaced femoral neck fractures. Qual Life Res. 2003;12(8): 1069-1079.

32. Gordon M, Paulsen A, Overgaard S, Garellick G, Pedersen AB, Rolfson O. Factors influencing health-related quality of life after total hip replacement - a comparison of data from the Swedish and Danish hip arthroplasty registers. BMC Musculoskelet Disord. 2013;14:316.

33. Alzahrani MM, Smith K, Tanzer D, Tanzer M. Primary total hip arthroplasty: equivalent outcomes in low and high functioning patients. J Am Acad Orthop Surg. 2016;24(11):814-822.

34. Shan L, Shan B, Graham D, Saxena A. Total hip replacement: a systematic review and meta-analysis on mid-term quality of life. Osteoarthritis Cartilage. 2014;22(3):389-406.
Clinical Interventions in Aging

\section{Publish your work in this journal}

Clinical Interventions in Aging is an international, peer-reviewed journal focusing on evidence-based reports on the value or lack thereof of treatments intended to prevent or delay the onset of maladaptive correlates of aging in human beings. This journal is indexed on PubMed Central, MedLine,

\section{Dovepress}

CAS, Scopus and the Elsevier Bibliographic databases. The manuscript management system is completely online and includes a very quick and fair peer-review system, which is all easy to use. Visit http://www.dovepress. com/testimonials.php to read real quotes from published authors. 